\title{
Attitudes of Consumers from the Mostar Canton in Bosnia and Herzegovina toward Advertising through Sport among the Question how Often they Participate in Sports Activities
}

\author{
Marin Corluka \\ University of Mostar, Faculty of Mathematics and Science Education, Mostar, Bosnia and Herzegovina \\ Dusko Bjelica and Marina Vukotic \\ University of Montenegro, Faculty for Sport and Physical Education, Niksic, Montenegro
}

\begin{abstract}
A B S T R A C T
Advertising is an attractive promotional tool for marketers who can use it to strengthen communication with consumers and persuade them to purchasing certain product or service. Hence, there is necessity to analyse their general attitudes among various questions, while this research was aimed at gaining relevant knowledge about the attitudes of Mostar consumers toward advertising through sport among the question how often they participate in sports activities. The sample included 228 respondents, divided into six subsample groups: consumers who do not participate in sport activities at all, then consumers who participate in sport activities less than ones a month, next 1-4 a month, 5-10 a month, 11-20 a month, as well as consumers participate in sport activities more than 20 times a month. The sample of variables contained the system of three general attitudes which were modelled by seven-point Likert scale. The results of the measuring were analysed by multivariate analysis (MANOVA) and univariate analysis (ANOVA) and Post Hoc test. Based on the statistical analyses it was found that significant differences occur at multivariate level, as well as between all three variables at a significance level of $p=.000$. Hence, it is interesting to highlight that it was found there are significant differences showed up between the consumers who participate in various sports activities. These results are so important for the marketers, mostly due to the reason they can't merge all the potential consumers who participate in various sports activities into one homogeneous group. This isthe case in previous investigations and this observation presents relevant information.
\end{abstract}

Key words: Attitudes, Advertising, Sports Events, Mostar

\section{Uvod}

Zaključci pionirskih studija iz navedene oblasti koji su objavljeni od strane Bauer-a i Greiser-a (Popović, 2011) i Lutz-a (Klačar, i Popović, 2010) pokrenuli su ideje koje se odnose na činjenicu da stavovi potrošača prema reklamiranju predstavljaju jedan od značajnih faktora koji mogu ojačati efikasnost reklamnih kampanja, uglavnom zbog razloga da kognitivna sposobnost potrošača prema reklamiranju jeste sadržana u njihovim osjećanjima i mislima (Muratović, Bjelica, \& Popović, 2014). Ako se nastavi sa istraživanjem ovog pitanja i ode se mnogo dublje, zanimljivo je da se primjećuje postojanje brojnih studija koje su istraživale stavove potrošača prema reklamiranju, ali većina njih smatra stavove potrošača prema reklamiranju samo uopšteno (Bjelica, i Popović, 2011; Popović, 2011b; Popović, Molnar, i Radovanović, 2011a; Popović, Matić, Milašinović, Jakšić, i Bjelica, 2015a; Popović, Matić, Milašinović, Hadžić, Milošević, i Bjelica, 2015b; Popović, Matić, Milašinović, Vujović, Milošević, i Bjelica, 2015c). U svakom slučaju, neki od njih su zaključili da su stavovi prema reklamiranju pokazali negativan trend tokom 1960-ih i 1970-ih (Popović, Bjelica, Jakšić, \& Georgiev, 2013; Popović, 2015; Popović, \& Milašinović, 2016), dok su drugi pronašli povoljnije stavove ispitanika u istom periodu (Popović, 2011). Ove nedosljednosti su navele na sumnju da reklamne kampanje koje koriste elemente iz specifičnih medijuma utiču na stavove potrošača prema reklamiranju u skladu sa tim (Popović, 2011). Neki autori su vjerovali da je jedan od najrelevantni- jih medija, upravo sport, odnosno sportisti i njihovi timovi, sportski događaji i sportski objekti (Bjelica i Popović, 2011; Mašanović, Zorić, \& Gardašević, 2017; Masanovic, Zoric, \& Gardasevic, 2018; Gardašević, Zorić, \& Mašanović, 2018), uglavnom iz razloga što ovi elementi mogu da utiču na stavove potrošača i naprave značajne oscilacije kod stavova u poređenju sa ostalim elementima (Bjelica, Popović, Jakšić, Hadžić, \& Akpinar, 2014b; Bjelica, i Popović, 2015a; Bjelica, \& Popović, 2015b; Bjelica, Gardašević, Vasiljević, \& Popović, 2016a; Bjelica, Gardašević, Vasiljević, \& Popović, 2016c; Zorić, Mašanović, \& Gardašević, 2017; Zorić, Mašanović, \& Gardašević 2018). Iz tog razloga, mnogi istraživači priznaju sport kao nezavisnu reklamnu platformu koju poslovni subjekti mogu koristiti kako bi prevazišli negativne stavove potrošača prema reklamiranju. Samim tim se postavilo i pitanje, kako bavljenje sportskim aktivnostima utiče na stavove potrošača prema reklamiranju u sportu kao jedan od niza problema sa kojim se nije susrećalo mnogo autora do sada (Bjelica, Popović, \& Akpinar, 2014a; Bjelica, Popović, \& Akpinar, 2015c; Bjelica, Popović, \& Akpinar, 2016b; Bjelica, Popović, \& Akpinar, 2017; Gardašević, Zorić, \& Mašanović, 2017), a to upravo i jeste cilj ove studije.

\section{Metod}

Populaciju u ovoj studiji su činili studenti sa Univerziteta u Mostaru koji su u vrijeme anketiranja, imali boravište na terito- 
riji Bosne i Hercegovine, dok je uzorak ispitanika organizovan putem kombinovanja ili raslojavanja, tako da su obrađena različita svojstva navedene populacije i različiti prostori na kojima je ona egzistirala.

Upitnici su distribuirani studentima osnovnih studija $u$ štampanom i elektronskom obliku. Ukupno je prikupljeno 233 upitnika, ali je 5 upitnika bilo isključeno iz analize, budući da nisu bili adekvatno popunjeni, tako da je u istraživanju učestvovalo, ukupno 228 ispitanika (slučajno odabranih studenta sa Univerziteta u Mostaru). Instrument istraživanja je predstavljao standardizovani upitnik (Popović, 2011) i sastojao se iz dva dijela, generalnih stavova prema reklamiranju u sportu i socio-demografskih karakteristika ispitanika kada je učestalost bavljenja sportskim aktivnostima tokom mjeseca u pitanju. Sistem promjenljivih u ovom upitniku je sadržao tri tvrdnje koje su ispitanici trebali da ocijene prema sedmo-stepenoj Likertovoj skali vrijednosti, kao i šest socio-demografskih karakteristika ispitanika (uopšte se ne bave, manje od jednom mjesečno, 1-4 puta mjesečno, 5-10 puta mjesečno, 11-20 puta mjesečno, i više od 20 puta mjesečno). Popunjavanje upitnika nije trajalo u prosjeku više od 10 minuta, a ispitanici su u anketi učestvovali na dobrovoljnoj osnovi. Važno je naglasiti da je anketa bila anonimna i da su svi odgovori bili strogo poverljivi. Vrijedno je napomenuti i da su ispitanici, i pored svega navedenog, imali mo- gućnost da u svakom momentu opozovu svoje učešće u anketi, ali se niko od njih nije na tako nešto odlučio.

Empirijski podaci su analizirani putem statističkog paketa za društvene nauke (SPSS 20.0), a kao prvi korak, bila je primijenjena deskriptivna statistika kojom su izračunati, prije svega frekvencija, zatim aritmetička sredina, standardna devijacija, kao i mjere asimetrije (Skewness) i spljoštenosti (Kurtosis) za svaku od tvrdnji. Budući da su se promjenljive u ovoj studiji nalazile na neparametrijskim skalama, radi detaljnijih analiza koje su slijedile, bilo je neophodno da se one, primjenom Blomovog postupka transformišu u skale višeg reda. Zatim su primjenom multivarijatne analize varijanse (MANOVA), univarijatne analize varijanse (ANOVA) i LSD Post Hoc testa, utvrđene razlike $u$ generalnim stavovima ispitanika prema reklamiranju u sportu u odnosu na učestalost bavljenja sportskim aktivnostima tokom mjeseca.

\section{Rezultati}

U prvoj tabeli su prikazani deskriptivni statistički podaci za sve tri tvrdnje koje su se odnosile na generalne stavove ispitanika prema reklamiranju u sportu. Prije svega, prikazana je aritmetička sredina koja oslikava pozitivne vrijednosti stavova kada su sve tri

Tabela 1. Generalni stavovi prema reklamiranju u sportu

\begin{tabular}{lcccccc}
\hline & \multirow{2}{*}{ Mean } & \multirow{2}{*}{ S.D. } & \multicolumn{2}{c}{ Skewness } & \multicolumn{2}{c}{ Kurtosis } \\
\cline { 4 - 7 } & & & Statistic & S.E. & Statistic & S.E. \\
\hline GSS1 & 4.25 & 2.116 & -.237 & .161 & -1.422 & .321 \\
GSS2 & 4.59 & 2.190 & -.403 & .161 & -1.349 & .321 \\
GSS3 & 4.32 & 1.756 & -.227 & .161 & -1.082 & .321 \\
\hline
\end{tabular}

Legenda:Mean - Aritmetička sredina; S.D. - Standardna devijacija;Skewness - Mjera asimetrije; Kurtosis - Mjera spljoštenosti; Statistic - Statistička vrijednost; S.E. - Standardna greška; GSS1 Moje opšte mišljenje je naklonjeno reklamiranju u sportu; GSS2 - Sveobuhvatno, smatram da je reklamiranje u sportu dobra stvar; GSS3 - Sveobuhvatno, da li ne volite ili volite reklamiranje u sportu

tvrdnje u pitanju, dok vrijednosti standardne devijacije pokazuju da elementi skupa, u prosjeku ne odstupaju značajno od aritme- tičke sredine. Kada se govori o mjerama asimetrije (Skewness) i spljostenosti (Kurtosis), negativne vrijednosti asimetrije kod svih

Tabela 2. Multivarijatna značajnost razlika u sistemu generalnih stavova prema reklamiranju u sportu kod ispitanika sa različitim navikama kada je bavljenje sportskim aktivnostima u pitanju

\begin{tabular}{llccc}
\hline & N & Mean & S.D. \\
\hline GSS1 & Ne bave se & 20 & 2.85 & 1.531 \\
& $<1$ & 20 & 4.40 & 1.603 \\
& $1-4$ & 22 & 3.36 & 1.529 \\
& -10 & 30 & 3.97 & 2.173 \\
& $11-20$ & 45 & 5.00 & 1.796 \\
& $>20$ & 91 & 4.46 & 2.373 \\
& Ukupno & 228 & 4.25 & 2.116 \\
\hline GSS2 & Ne bave se & 20 & 3.05 & 1.356 \\
& $<1$ & 20 & 4.75 & 1.803 \\
& $1-4$ & 22 & 3.41 & 1.919 \\
& $5-10$ & 30 & 4.30 & 2.351 \\
& $11-20$ & 45 & 5.33 & 1.895 \\
& $>20$ & 91 & 4.91 & 2.313 \\
& Ukupno & 228 & 4.59 & 2.190 \\
\hline GSS3 & Ne bave se & 20 & 3.05 & 1.356 \\
& $<1$ & 20 & 4.85 & 1.040 \\
& $1-4$ & 22 & 2.41 & 1.297 \\
& $5-10$ & 30 & 4.43 & 1.455 \\
& $11-20$ & 45 & 4.62 & 1.862 \\
& $>20$ & 91 & 4.76 & 1.682 \\
& Ukupno & 228 & 4.32 & 1.756 \\
\hline
\end{tabular}


promjenljivih pokazuju da je većina rezultata desno od srednje vrijednosti, među većim vrijednostima, dok negativne vrijednosti spljoštenosti kod svih promjenljivih pokazuju da je raspodjela pljosnatija od normalne tj. da ima više rezultata nagomilanih na repovima raspodjele.

U nastavku ove studije su prikazani komparativni statistički podaci generalnih stavova prema reklamiranju u sportu koji su dobijeni primjenom multivarijatne analize varijanse (MANOVA), univarijatne analize varijanse (ANOVA) i LSD Post Hoc testa, a u cilju utvrđivanja razlike u generalnim stavovima ispitanika prema reklamiranju u sportu u odnosu na učestalost ba- vljenja sportskim aktivnostima.

Inspekcijom druge tabele u kojoj su prikazani rezultati multivarijatne analize, jasno se uočava da u cijelom sistemu upoređivanih parametara postoji statistički značajna razlika u generalnim stavovima prema reklamiranju u sportu u odnosu na učestalost bavljenja sportskim aktivnostima $(\mathrm{p}=.000)$.

Inspekcijom treće tabele u kojoj su prikazani rezultati univarijatne analize, jasno se uočava da je došlo do statistički značajnih razlika u generalnim stavovima prema reklamiranju u sportu u odnosu na učestalost bavljenja sportskim aktivnostima kod sve tri promenljive.

Tabela 3. Univarijatna značajnost razlika u sistemu generalnih stavova prema reklamiranju u sportu kod ispitanika sa različitim navikama kada je bavljenje sportskim aktivnostima u pitanju

\begin{tabular}{ccc}
\hline & F & p \\
\hline GSS1 & 4.245 & .001 \\
GSS2 & 5.265 & .000 \\
GSS3 & 11.126 & .000 \\
\hline
\end{tabular}

Inspekcijom naredne tri tabele gdje su prikazani rezultati Post Hoc testa koji ukazuju na značajnost razlika između parova pojedinačnih entiteta sa različitim navikama kada je bavljenje sportskim aktivnostima u pitanju za svaku promjenljivu, bu- dući na rezultate koji su se pojavili na univarijatnom nivou, očekivano se uočava da postoje statistički značajne razlike pojedinih parametara.

Tabela 4. Utvrđivanje značajnih razlika u sistemu generalnih stavova prema reklamiranju u sportu primjenom Post Hoc testa između pojedinačnih entiteta sa različitim navikama kada je bavljenje sportskim aktivnostima u pitanju kod tvrdnje „,moje opšte mišljenje je naklonjeno reklamiranju u sportu“"

\begin{tabular}{cccccc}
\hline vs & Ne bave se & $<\mathbf{1}$ & $\mathbf{1 - 4}$ & $\mathbf{5 - 1 0}$ & $\mathbf{1 1 - 2 0}$ \\
\hline$<1$ & .017 & & & & \\
$1-4$ & .417 & .102 & & & \\
$5-10$ & .060 & .464 & .295 & & \\
$11-20$ & .000 & .276 & .002 & .033 & \\
$>20$ & .002 & .903 & .025 & .252 & .150 \\
\hline
\end{tabular}

Došlo se do zaključka da se kod prve tvrdnje ,moje opšte mišljenje je naklonjeno reklamiranju u sportu“ javljaju razlike izme-

đu ispitanika koji se ne bave sportskim aktivnostima i između grupa ispitanika koji se bave sportskim aktivnostima manje od 1

Tabela 5. Utvrđivanje značajnih razlika u sistemu generalnih stavova prema reklamiranju u sportu primjenom Post Hoc testa između pojedinačnih entiteta sa različitim navikama kada je bavljenje sportskim aktivnostima u pitanju kod tvrdnje „,sveobuhvatno, smatram da je reklamiranje u sportu dobra stvar"

\begin{tabular}{cccccc}
\hline vs & Ne bave se & $<\mathbf{1}$ & $\mathbf{1 - 4}$ & $\mathbf{5 - 1 0}$ & $\mathbf{1 1 - 2 0}$ \\
\hline$<1$ & .011 & & & & \\
$1-4$ & .579 & .039 & & & \\
$5-10$ & .040 & .457 & .131 & & \\
$11-20$ & .000 & .301 & .001 & .037 & \\
$>20$ & .000 & .754 & .003 & .166 & .271 \\
\hline
\end{tabular}

puta mjesečno, 11-20 i preko 20 puta mjesečno. Takođe razlike se javljaju između ispitanika koji se bave sportskim aktivnostima 1-4 puta mjesečno i onih grupa koje se bave sportskim aktivnostima 11-20 i preko 20 puta mjesečno. Na kraju razlike još primjećujemo između ispitanika koji se bave sportskim aktivnostima 5-10 i 11-20 puta mjesečno. Pozitivnije rezultate vidimo kod dvije grupe koje se najviše bave sportskim aktivnostima, najmane pozitivne kod grupe koja se ne bavi sportom.

Tabela 6. Utvrđivanje značajnih razlika u sistemu generalnih stavova prema reklamiranju u sportu primjenom Post Hoc testa između pojedinačnih entiteta sa različitim navikama kada je bavljenje sportskim aktivnostima u pitanju kod tvrdnje „sveobuhvatno, da li ne volite ili volite reklamiranje u sportu“"

\begin{tabular}{cccccc}
\hline vs & Ne bave se & $<\mathbf{1}$ & $\mathbf{1 - 4}$ & $\mathbf{5 - 1 0}$ & $\mathbf{1 1 - 2 0}$ \\
\hline$<1$ & .000 & & & & \\
$1-4$ & .193 & .000 & & & \\
$5-10$ & .003 & .364 & .000 & & \\
$11-20$ & .000 & .594 & .000 & .614 & \\
$>20$ & .000 & .815 & .000 & .332 & .639 \\
\hline
\end{tabular}

Došlo se do zaključka da se kod druge tvrdnje ,,sveobuhvatno, smatram da je reklamiranje u sportu dobra stvar" javljaju razlike između ispitanika koji se ne bave sportskim aktivnostima i između grupa ispitanika koji se bave sportskim aktivnosti- 
ma manje od 1 puta mjesečno, 5-10, 11-20 i preko 20 puta mjesečno; između ispitanika koji se bava sportskim aktivnostima 14 puta mjesečno i onih grupa koje se sportskim aktivnostima bave 11-20 i preko 20 puta mjesečno; između ispitanika koji se bave sportskim aktivnostima manje od 1 put mjesečno i $1-4$ puta mjesečno; između ispitanika koji se bave sportskim aktivnostima 5-10 puta mjesečno i 11-20 puta mjesečno. Pozitivnije rezultate vidimo kod dvije grupe koje se najviše bave sportskim aktivnostima, najmane pozitivne kod grupe koja se ne bavi sportom.

Došlo se do zaključka da se kod treće tvrdnje „sveobuhvatno, da li ne volite ili volite reklamiranje u sportu“ javljaju razlike između ispitanika koji se ne bave sportskim aktivnostima i između grupa ispitanika koji se bave sportskim aktivnostima manje od 1 puta mjesečno, 5-10, 11-20 i preko 20 puta mjesečno. Takođe razlike se javljaju između ispitanika koji se bave sportskim aktivnostima 1-4 puta mjesečno i između grupa ispitanika koji se bave sportskim aktivnostima 5-10, 11-20 i preko 20 puta mjesečno. Na kraju, razlike se javljaju između ispitanika koji se bave sportskim aktivnostima manje od 1 puta mjesečno i entieta koji se bave sportskim aktivnostima od 1-4 puta mjesečno. Pozitivnije rezultate vidimo kod dvije grupe koje se najviše bave sportskim aktivnostima, najmane pozitivne kod grupe koja se bavi sportom 1-4 puta mjesečno.

\section{Diskusija}

S obzirom da su rezultati pokazali da ispitanici imaju veoma pozitivan stav prema reklamiranju u sportu što potvrđuje visoka vrijednost aritmetičke sredine za sve tri promjenljive, kao i da skoro dvije trećine ispitanika imaju pozitivan stav prema reklamiranju u sportu što se ogleda u izrazito negativnim vrijednostima mjera asimetrije, trebalo bi naglasiti da su ovi rezultate usaglašeni sa rezultatima prethodnih istraživanja (Molnar, Lilić, Popović, Akpinar, \& Jakšić, 2011; Popović, Jakšić, Matić, Bjelica, \& Maksimović, 2014; Popović, Bjelica, Georgiev, \& Akpinar, 2011b; Popović, Matić, Milašinović, Jakšić, \& Bjelica, 2015d; Popović, Matić, Milašinović, Hadžić, Milošević, \& Bjelica, 2015e; Popović, Matić, Milašinović, Vujović, Milošević, \& Bjelica, 2015f; Popović, Jakšić, Matić, Bjelica, \& Maksimović, $2015 \mathrm{~g}$ ), i da ne postoje značajne razlike koje bi trebalo po-

\section{R E F E R E N C E S}

Bjelica, D., i Popović, S. (2011). Stavovi potrošača prema reklamiranju u sportu u odnosu na učestalost posmatranja sportskih događaja. Sportske nauke i zdravlje, 1(2), 114119.

Bjelica, D., Popović, S., \& Akpinar, S. (2014a). Book of Abstracts of the 11th International Scientific Conference on Transformation Process in Sport "Sport Performance". Podgorica: Montenegrin Sports Academy.

Bjelica, D., Popović, S., Jakšić, D., Hadžić, R., \& Akpinar, S. (2014b). How Does Advertising through Sport Work? Evidence from Turkey. In Proceedings book of the 7th International Scientific Conference on Kinesiology "Fundamental and Applied Kinesiology - Steps Forward " (477). Opatija: University of Zegreb, Faculty of Kinesiology.

Bjelica, D., i Popović, S. (2015a). Evolucija reklamiranja sa posebnim osvrtom na reklamiranje u sportu. Sport Mont, $13(43,44,45), 35-41$

Bjelica, D., \& Popović, S. (2015b). Evolution of Advertising with a Specific Retrospection at Sport Advertising. In Book menuti. Dobijeni rezultati, takođe jasno ukazuju da ispitanici koji žive na različitim lokacijama, kao što su Sjedinjene države, Turska, Crna Gora, Srbija, i Bosna i Hercegovina, imaju pozitivne stavove prema reklamiranju u sportu, dok je, ipak, poređenja radi, vrijedno navesti da prema Mittal-u (Popović, 2011), različite studije ukazuju na negativne stavove kada je reklamiranje proizvoda u tradicionalnim industrijama u pitanju. Prema tome, više je nego evidentno da je primjena sporta u savremenoj poslovnoj komunikaciji uticala da se generalni stavovi potrošača značajno promijene kada je reklamiranje u pitanju, a prepoznavanje privlačnosti sporta je omogućilo poslovnim organizacijama da se približe sportskim potrošačima i na mnogo bezbolniji način utiču na njihovo ponašanje.

Utvrđivanjem razlike u generalnim stavovima ispitanika prema reklamiranju u sportu u odnosu na učestvovanje u sportskim aktivnostima, u ovoj studiji su pronađene razlike u stavovima između ispitanika koji imaju različite navike kada je u pitanju učestvovanje u sportskim aktivnostima. Ove razlike su se pojavile kod sve tri promjenljive na univarijatnom nivou. Kod dvije promenljive ,moje opšte mišljenje je naklonjeno reklamiranju u sportu“, i ,sveobuhvatno, smatram da je reklamiranje u sportu dobra stvar"najpozitivnije rezultate vidimo kod dvije grupe koje se najviše bave sportskim aktivnostima, najmane pozitivne kod grupe koja se ne bavi sportom. Kod treće promenljiive ,sveobuhvatno, da li ne volite ili volite reklamiranje u sportu", najpozitivnije rezultate vidimo kod dvije grupe koje se najviše bave sportskim aktivnostima, najmane pozitivne kod grupe koja se bavi sportom 1-4 puta mjesečno.

$\mathrm{Na}$ osnovu statističkih analiza, utvrđeno je da se značajne razlike javljaju na multivarijatnom nivou, kao i između većine varijabli na univarijatnom nivou značajnosti od $p=.00$. Pronađene značajne razlike između ispitanika sa različitom učestalošću u bavljenju sportskim aktivnostima, slažu se sa prethodnim studijama (Bjelica i sar., 2014b; Bjelica, i Popović, 2015a; Bjelica, i Popović, 2015b; Bjelica i sar., 2016a; Bjelica i sar., 2016c; Gardašević, Zorić, \& Mašanović, 2017). Ovi rezultati su veoma važni za poslovne subjekte u Crnoj Gori i za naučnu javnost, uglavnom iz razloga što ne mogu spojiti sve potencijalne potrošače koji učestvuju u raznim sportskim aktivnostima u jednu homogenu grupu, o čemu govore i prethodna istraživanja (Bjelica i sar., 2016a; Bjelica i sar., 2016c).

of Abstracts of the 12th International Scientific Conference on Transformation Process in Sport "Sport Performance" (60-61), Podgorica: Montenegrin Sports Academy.

Bjelica, D., Popovic, S., \& Akpinar, S. (2015c). Book of Abstracts of the 12th International Scientific Conference on Transformation Process in Sport "Sport Performance". Podgorica: Montenegrin Sports Academy.

Bjelica, D., Gardašević, J., Vasiljević, I., \& Popović, S. (2016a). Ethical Dilemmas of Sport Advertising. Sport Mont, 14(3), 41-43.

Bjelica, D., Popović, S., \& Akpinar, S. (2016b). Book of Abstracts of the 13th International Scientific Conference on Transformation Process in Sport "Sport Performance". Podgorica: Montenegrin Sports Academy.

Bjelica, D., Gardašević, J., Vasiljević, I., \& Popović, S. (2016c). Ethical dilemmas of sport advertising. In Book of Abstracts of the 13th International Scientific Conference on Transformation Process in Sport "Sport Performance" (41), Podgorica: Montenegrin Sports Academy. 
Bjelica, D., Popovic, S., \& Akpinar, S. (2017). Book of Abstracts of the 14th International Scientific Conference on Transformation Process in Sport "Sport Performance". Podgorica: Montenegrin Sports Academy.

Gardaševic, J., Zorić, G., \& Mašanović, B. (2017). Attitudes of Turkish consumers toward advertising through sport among the question how often they participate in sports activities. Journal of Anthropology of Sport and Physical Education, 1(1), 23-27.

Gardašević, J., Zorić, G., \& Mašanović, B. (2018). Attitudes of Montenegrin consumers toward advertising through sport among the question how often they participate in sports activities. Journal of Anthropology of Sport and Physical Education, 2(1), 15-19.

Klačar, M. i Popović, S. (2010). Reklamiranje u sportu kao efektivno sredstv osavremene komunikacije. Teme, 4, 12191230.

Mašanovic, B., Zorić, G., \& Gardašević, J. (2017). Attitudes of Turkish consumers toward advertising through sport among the frequency of watching sports events. Journal of Anthropology of Sport and Physical Education, 1(1), 3-7.

Mašanović, B., Zorić, G., \& Gardašević, J. (2018). Attitudes of Montenegrin consumers toward advertising through sport among the frequency of watching sports events. Journal of Anthropology of Sport and Physical Education, 2(1), 9-13.

Molnar, S., Lilić, Lj., Popović, S., Akpinar, S., \& Jakšić, D. (2011). Attitudes of various demographic groups toward advertising through sport at METU. Facta Universitatis, Series: Physical Education and Sport, 9(3), 255-263.

Muratović, A., Bjelica, D., \& Popović, S. (2014). Examining beliefs and attitudes toward advertising through sport among montenegrin consumers. Facta Universitatis, Series: Physical Education and Sport, 12(2), 95-104.

Popović, S. (2011). Reklamiranje u sportu kao efektivno sredstvo savremene poslovne komunikacije. Neobjavljena doktoska disertacija, Novi Sad: Univerzitet u Novom Sadu.

Popović, S. (2011b). Stavovi potrošača prema reklamiranju u sportu u odnosu na učestalost kupovine sportskih proizvoda. Sport Mont, 9(28,29,30), 140-147.

Popović, S., Molnar, S. i Radovanović, D. (2011a). Stavovi potrošača prema reklamiranju u sportu u odnosu na učestalost bavljenja sportskim aktivnostima. Sport Mont, 9(28,29,30), 148-155.

Popović, S., Bjelica, D., Georgiev, G., \& Akpinar, S. (2011b). Comparison of attitudes toward advertising through sport between Montenegrin and Turkish stakeholders. In Proceedings book of the 6th International Scientific Conference on Kinesiology "Integrative Power of Kinesiology" (612). Opatija: University of Zegreb, Faculty of Kinesiology.

Popović, S., Jakšić, D., Matić, R., Bjelica, D., \& Maksimović, N. (2014). Examining Beliefs and Attitudes toward Advertising through Sport among Serbian Consumers. In Book of abstracts of International conference "Economics and Management of Sports 2014” (pp. 11-12). Brno: Faculty of Sports Studies.

Popović, S., Bjelica, D., Jakšić, D, \& Georgiev, G. (2013). How does Advertising Through Sport Work? Evidence from
Montenegro. In Book of Abstracts of the $18^{\text {th }}$ Annual Congress of the European College of Sport Science (444-445), Barcelona: National Institute of Physical Education of Catalonia.

Popović, S., Matić, R., Milašinović, R., Jakšić, D., i Bjelica, D. (2015a). Stavovi srbijanskih potrošača prema reklamiranju u sportu u odnosu na učestalost bavljenja sportskim aktivnostima. Sport Mont, 13(43,44,45), 50-56.

Popović, S., Matić, R., Milašinović, R., Hadžić, R., Milošević, Z., i Bjelica, D. (2015b). Stavovi srbijanskih potrošača prema reklamiranju u sportu u odnosu na učestalost kupovine sportskih proizvoda. Sport Mont, 13(43,44,45), 262-269.

Popović, S., Matić, R., Milašinović, R., Vujović, D., Milošević, Z. i Bjelica, D. (2015c). Stavovi srbijanskih potrošača prema reklamiranju u sportu u odnosu na učestalost posmatranja sportskih događaja. Sport Mont, 13(43,44,45), 270-276.

Popović, S., Matić, R., Milašinović, R., Jakšić, D., \& Bjelica, D. (2015d). Attitudes of Serbian Consumers toward Advertising through Sport among the Question How Often They Participate in Sports Activities. In Book of Abstracts of the 12th International Scientific Conference on Transformation Process in Sport "Sport Performance" (58-59), Podgorica: Montenegrin Sports Academy.

Popović, S., Matić, R., Milašinović, R., Hadžić, R., Milošević, Z., \& Bjelica, D. (2015e). Attitudes of Serbian Consumers toward Advertising through Sport among the Question How Often Consumers Purchase Sporting Goods. In Book of Abstracts of the 12th International Scientific Conference on Transformation Process in Sport "Sport Performance" (5960), Podgorica: Montenegrin Sports Academy.

Popović, S., Matić, R., Milašinović, R., Vujović, D., Milošević, Z., \& Bjelica, D. (2015f). Attitudes of Serbian Consumers toward Advertising through Sport among the Frequency of Watching Sports Events. In Book of Abstracts of the 12th International Scientific Conference on Transformation Process in Sport "Sport Performance" (60), Podgorica: Montenegrin Sports Academy.

Popović, S., Jakšić, D., Matić, R., Bjelica, D., \& Maksimović, N. (2015g). Examining Beliefs and Attitudes toward Advertising through Sport among Serbian Consumers. Studia Sportiva, 9(1), 225-231.

Popović, S. (2015). Sport Nowadays (In Montenegrin). In D. Bjelica (Ed.), Advertising Role of Sponsorship in Modern Sport (pp. 111-116). Podgorica: Montenegrin Sports Academy.

Popović, S. \& Milašinović, R. (2016). Model of Advertising Communication in Sport. Sport Mont, 14(1), 33-38.

Zorić, G., Mašanović, B., \& Gardašević, J. (2017). Attitudes of Turskish consumers toward advertising through sport among the question how often consumers purchase sporting goods. Journal of Anthropology of Sport and Physical Education, 1(1), 17-21. doi: 10.26773/jaspe.17100.

Zorić, G., Mašanović, B., \& Gardašević, J. (2018). Attitudes of Montenegrin consumers toward advertising through sport among the question how often consumers purchase sporting goods. Journal of Anthropology of Sport and Physical Education, 2(1), 21-25.

M. Corluka

University of Montenegro, Faculty for Sport and Physical Education, Narodne omladine bb, Niksic, Montenegro e-mail:marinavuk@ac.me 
